\title{
Physical therapy in adolescents with knee injuries treated with arthroscopy: our experience and literature review
}

CATAN Liliana ${ }^{1,2}$, NEGRU Marius ${ }^{2}$

1 "Victor Babeș" University of Medicine and Pharmacy, Timișoara, Romania

${ }^{2}$ Paediatric Surgery, Louis Țurcanu Children’s Hospital Timișoara, Romania

Corresponding author: CATAN Liliana, E-mail: catan.liliana@umft.ro

\begin{abstract}
If not treated adequately, the knee injuries in adolescents can cause long-term functional impairments. The aim of our study was to quantify the functioning capacity in children who suffered soft tissues and/or bone lesions of the knee treated by arthroscopy. We reviewed the medical charts of 5 adolescent patients diagnosed with sport knees injuries, admitted in our clinic in the last two years. Arthroscopy was made three weeks after the injury. Afterwards, they were addressed to the Rehabilitation Department and followed the physical exercise programme. The patients were assessed at the beginning of rehabilitation and after 3 months: knee ROM (flexion and extension deficit) and International Knee Documentation Committee (IKDC) subjective evaluation. At the final assessment all patients presented significantly improvements in knee range of motion and functional capacity. Arthroscopic surgery, followed by a tailored rehabilitation programme, is important in the management of adolescents with knee injuries.
\end{abstract}

Key words: knee injury, arthroscopy, rehabilitation,

\section{Introduction}

The knee joint is frequently affected in the young athletes. In comparison to adult patients, children have relative weak points at their physes and apophyses. This fact causes different forces applied on ligaments and bones during injury. When assessed on imaging the following pathologic changes are frequently met: patellar and patellar tendon injury, physeal fractures, osteochondral abnormality, ligament tears, and meniscal lesions [1].

The meniscal resection is performed more often than the repair [2]. However, as the meniscus has an important role in maintaining knee function and preventing arthritis, meniscal preservation surgery must be considered, especially in paediatric patients [3].

If not treated adequately, the knee injuries in adolescents can cause long-term functional impairments. The aim of our study was to quantify the functioning capacity in children who suffered soft tissues and/or bone lesions of the knee, treated by arthroscopy.

\section{Methods}

We reviewed the medical charts of 5 adolescent patients diagnosed with sport knee injuries, admitted in our clinic in the last two years. All our patients have been addressed to arthroscopy. Two patients had meniscal tears, one patient had intra-articular supracondylar distal femoral fracture; in two patients no lesion was notice. They were males with a mean age of 16.6 years. One was practising competitive sport (football); the other 4 were practising recreational sport (football, skiing) and were overweight or obese.

Arthroscopy was performed a medium of three weeks after the injury. The meniscus tears were treated conservatively, and the fragments of meniscus or the cartilage after chondral fractures were removed. Afterwards, the patients were addressed to the Rehabilitation Department and followed the physical exercise programme.

The rehabilitation consisted in 10 daily sessions performed in the outpatient Rehabilitation Department. The patients followed electrotherapy procedures (transcutaneous electrical nerve stimulation and medium frequency electrotherapy) in order to reduce the pain and to decrease the swelling [4]. The exercise programme (Fig 1) was composed by passive knee range of motion, wall slides and passive heel slides, isometrics of the quadriceps and hamstring, heel raises, partial squats, low-resistance stationary cycling and gait training. The patients continued the 10 sessions with a programme consisting in supervised exercises (3 times per week for 10 weeks), namely closed-chain 
exercises, mini-squats, balance activities, balance board, stair-stepping and treadmill.

The patients were assessed at the beginning of rehabilitation and after 3 months: knee range of motion (flexion range of motion and extension deficit) and International Knee Documentation
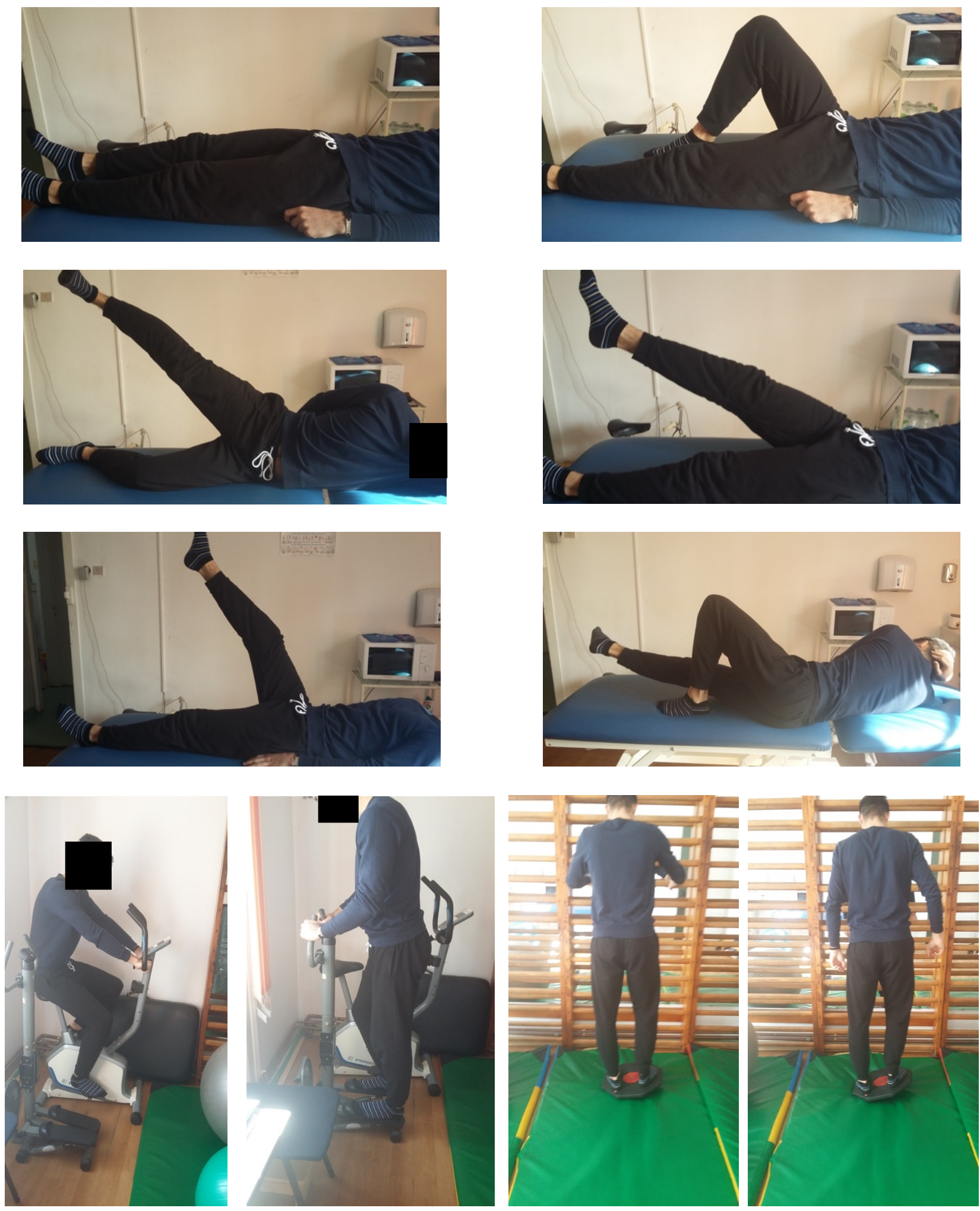

Figure 1. Rehabilitation exercises

Committee (IKDC) subjective evaluation [5,6]. IKDC has been proved to be a reliable patientreported measure in patients with knee disorders $[7,8]$. Patient-reported measures are very useful in clinical practice, providing information about pain, function, quality of life and activity level [7,9-11].
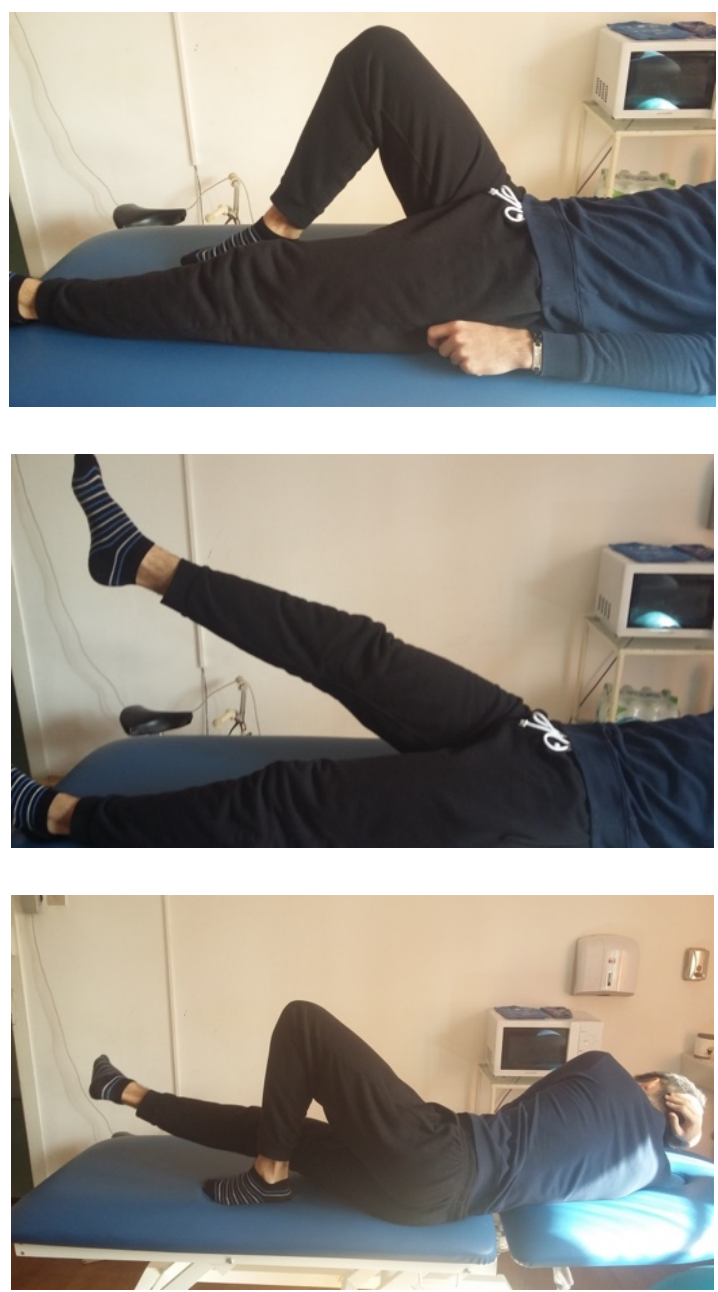


\section{Results}

At the final assessment all patients presented significantly improvements in knee range of motion and functional capacity (Table 1). The best results were in adolescents with meniscal lesions (patients no 1 and 2). The patient with supracondylar distal femoral fracture (patient no 3) required a longer rehabilitation period. In comparison to the other patients he presented deficits of knee range of motion and functioning after 3 months.

Table 1. Functional and range of motion assessment

\begin{tabular}{|l|l|l|l|l|l|l|}
\hline & \multicolumn{3}{|l|}{ Initial assessment } & \multicolumn{3}{l|}{ 3-month assessment } \\
\cline { 2 - 7 } & $\begin{array}{l}\text { IKDC } \\
\text { Score }\end{array}$ & $\begin{array}{l}\text { Extension } \\
\text { deficit }\end{array}$ & $\begin{array}{l}\text { Flexion } \\
\text { ROM }\end{array}$ & $\begin{array}{l}\text { IKDC } \\
\text { Score }\end{array}$ & $\begin{array}{l}\text { Extension } \\
\text { deficit }\end{array}$ & $\begin{array}{l}\text { Flexion } \\
\text { ROM }\end{array}$ \\
\hline $\begin{array}{l}\text { Patient } \\
\text { no 1 }\end{array}$ & 19.5 & $10^{\circ}$ & $90^{\circ}$ & 74.7 & 0 & $140^{\circ}$ \\
\hline $\begin{array}{l}\text { Patient } \\
\text { no 2 }\end{array}$ & 21.8 & $10^{\circ}$ & $70^{\circ}$ & 67.8 & 0 & $140^{\circ}$ \\
\hline $\begin{array}{l}\text { Patient } \\
\text { no 3 }\end{array}$ & 16.1 & $15^{\circ}$ & $70^{\circ}$ & 57.4 & $5^{\circ}$ & $125^{\circ}$ \\
\hline
\end{tabular}

IKDC: International Knee Documentation

Committee; ROM: range of motion

\section{Discussion}

Shieh et al. [12] demonstrated that factors such as male gender and obesity are associated with a greater complexity of the knee meniscus tear in paediatric patients. With the increasing youth participation in sports activities, a greater number of meniscal lesions have been seen in children and adolescents [12]. Almost $80-90 \%$ of meniscal lesions are due to sports activities, being associated with anterior cruciate ligament tears, condral lesions or tibial fractures [13].

In a retrospective study, Shieh et al. [12] analysed a sample of 293 patients aged between 10 and 19 years with arthroscopic interventions for meniscal tears and associated lesions (41\% were children with a mean age of 13.5 years and 59\% adolescents with a mean age of 16.4 years). The rate of associated ligament injuries was of $28 \%$ in children compared with $51 \%$ in adolescents. Complex tears were observed in $28 \%$ cases, followed by vertical $(16 \%)$, discoid (14\%), bucket-handle $(14 \%)$, radial $(10 \%)$, horizontal $(8 \%)$, oblique $(5 \%)$ or fray tears $(3 \%)$, and root detachment $(2 \%)$. Complex tears were seen most frequently in boys (32\% versus $20 \%$ in girls) and in subjects with increased body mass index (27.4 versus $25.1 \mathrm{~kg} / \mathrm{m}^{2}$ in those with noncomplex tears), for both males and females. Surgical repair was performed in $46 \%$ of all cases $(56 \%$ in those treated within 3 months from injury versus $42 \%$ in those treated after 6 months). There was no difference in the repair rate between the two age groups (49\% in children versus $46 \%$ in adolescents). Authors suggested that an earlier treatment of the meniscal lesions could increase the probability of repair in younger patients.

Wessel et al. [14] in a 10-year retrospective study found 1273 patients aged below 16 years $(61.3 \%$ males) that presented themselves in the emergency compartments for traumatic knee injuries. The most frequent lesions were soft-tissue lesions (82\%), followed by hemarthrosis (18\%). The authors divided the patients in three groups based on their age - patients under 10 years $(n=528$, with metaphyseal fractures and patellar dislocations; hemarthrosis only in 5.7\% cases), patients aged 11 12 years $(n=207$, with patellar dislocations and fracture and hemarthrosis in $17.9 \%$ cases), and patients aged 13-16 years $(n=538$, diagnosed with intra-articular fractures, patellar fractures and dislocations, ligamentous and meniscal tears, with hemarthrosis in $30.3 \%$ cases). The ligamentous lesions were observed in 16 cases and the meniscal lesions in 2 cases. Arthroscopy was found to be justified only in those older than 13 years.

Our study, although including a small number of patients, had male adolescents practicing performance sport or recreational sport activities. Compared with adult patients, in children and adolescence over $90 \%$ of patients can return to sport after knee injuries, even when the anterior cruciate ligament needs reconstruction $[15,16]$.

In 2019, Bauer et al. [17] reviewed the high-school athletes with knee injuries who underwent arthroscopic knee injuries. The authors noticed a lower rate for sport return after one year at the preinjury level for those undergoing anterior cruciate ligament reconstruction $(\mathrm{n}=225)$ in comparison to those with knee arthroscopy $(n=74)$. The rates of return to play were lower in senior high school athletes compared to those within grades 9 and 11 , for both anterior cruciate ligament reconstruction and knee arthroscopy.

There are a lot of individuals that cannot return to play after knee injuries with anterior cruciate ligament reconstruction, due to recurrent injuries or osteoarthritis. Sepulveda et al. [16] showed that $81 \%$ individuals with anterior cruciate ligament reconstruction return to sport, $65 \%$ return to the preinjury level and $55 \%$ return to a competitive level. They identified a risk of $5.8 \%$ of homolateral retears and a rate of $11.8 \%$ of contralateral tear. 
Between $20 \%$ and $50 \%$ of patients will develop knee osteoarthritis in the next 10-20 years. The surgery timing, individualized protocols of play return and injury prevention programmes are very important factors for reducing complications and for obtaining improved percentages of the return to play.

Testing for the return to play after anterior cruciate ligament reconstruction represents an essential part of the rehabilitation programme. Sousa et al. [18] reported that patients with excellent results on isokinetic strength and functional testing at 6 months after anterior cruciate ligament reconstruction were at higher risk of contralateral anterior cruciate ligament injuries. In conclusion, the optimal return to play evaluation is very important for preventing further injuries.

In the current study, the adolescent who practiced football (patient no 1) had the best functional results and return to competitive sport 3 months after surgery.

Due to the skeletal and joint particularities in children, the pattern of the knee injuries is slightly different in comparison to adults. Therefore, the indication for surgical treatment and rehabilitation has some particularities [19].

Rehabilitation therapy is a crucial component in the management of anterior cruciate ligament injuries, with or without reconstruction. Rehabilitation programme should be individualized based on the type of injury and age, on the physiological and psychological maturity, as well as on balance and functional testing [20-22]. The level of expectation regarding the amount of time and information for performing physical therapy can also represent a factor in the assessment of the rehabilitation efficacy [23].

There is evidence that early reconstruction after anterior cruciate ligament rupture is necessary; for other types of knee lesions, like meniscus tears or chondral fractures, there is yet no consensus regarding the benefits of the early surgical treatment $[15,16,19,24]$. In our series, the arthroscopies were made for demonstrated or suspicion of free intraarticular fragments after the initial injuries. After the extraction of these free intraarticular fragments, when demonstrated, and with appropriate medical and rehabilitation treatment the patients' evolution was favourable. Therefore, we believe that a more conservative approach is in the benefit of this category of patients.

Functional capacity represents an important parameter to be assessed in adolescents who are involved in sports activities. It can be diminished due to either musculoskeletal injuries or pulmonary involvement [25].

\section{Conclusions}

Arthroscopic surgery, followed by a tailored rehabilitation programme, is important in the management of adolescents with knee injuries. This has in view not only the return to sport competition, but also the maintenance of a proper knee functioning for future professional and recreational activities.

\section{References}

1. Leschied, J.; Udager, K.G. Imaging of the Pediatric Knee. Semin. Musculoskelet. Radiol. 2017, 21, 137-146.

2. Tuckman, D.; Bravman, J.; Lee, S.; Rosen, J.; Sherman, O. Outcomes of Meniscal Repair:Minimum of 2-year Follow-up. Bull Hosp Jt Dis 2006, 63, 100-104.

3. Majeed, H.; Karuppiah, S.; Sigamoney, K.V.; Geutjens, G.; Straw, R.G. All-inside meniscal repair surgery: factors affecting the outcome. $J$. Orthop. Traumatol. 2015, 16, 245-249.

4. Bjordal, J.M.; Johnson, M.I.; Ljunggreen, A.E. Transcutaneous electrical nerve stimulation (TENS) can reduce postoperative analgesic consumption. A meta-analysis with assessment of optimal treatment parameters for postoperative pain. Eur. J. Pain 2003, 7, 181188.

5. Anderson, A.F.; Irrgang, J.J.; Kocher, M.S.; Mann, B.J.; Harrast, J.J. The International Knee Documentation Committee Subjective Knee Evaluation Form: Normative Data. Am. J. Sports Med. 2006, 34, 128-135.

6. Todor, A.; Vermesan, D.; Haragus, H.; Patrascu Jr, J.M.; Timar, B.; Cosma, D.I. Cross-cultural adaptation and validation of the Romanian International Knee Documentation Committeesubjective knee form. PeerJ 2020, 8, e8448e8448.

7. Collins, N.J.; Misra, D.; Felson, D.T.; Crossley, K.M.; Roos, E.M. Measures of knee function: International Knee Documentation Committee (IKDC) Subjective Knee Evaluation Form, Knee Injury and Osteoarthritis Outcome Score (KOOS), Knee Injury and Osteoarthritis Outcome Score Physical Function Short Form (KOOS-PS), Knee Outcome Survey Activities of Daily Living Scale (KOS-ADL), Lysholm Knee Scoring Scale, Oxford Knee Score (OKS), 
Western Ontario and McMaster Universities Osteoarthritis Index (WOMAC), Activity Rating Scale (ARS), and Tegner Activity Score (TAS). Arthritis Care Res. (Hoboken). 2011, 63 Suppl 11, S208-S228.

8. Crawford, K.; Briggs, K.K.; Rodkey, W.G.; Steadman, J.R. Reliability, Validity, and Responsiveness of the IKDC Score for Meniscus Injuries of the Knee. Arthroscopy 2007, 23, 839-844.

9. Lam, K.C.; Thomas, S.S.; Valier, A.R.S.; McLeod, T.C.V.; Bay, R.C. Previous Knee Injury and Health-Related Quality of Life in Collegiate Athletes. J. Athl. Train. 2017, 52, 534-540.

10. Jones, R.S.; Stukenborg, G.J. Patient-Reported Outcomes Measurement Information System (PROMIS) Use in Surgical Care: A Scoping Study. J. Am. Coll. Surg. 2017, 224, 245254.e1.

11. Cevei, M.; Onofrei, R.R.; Cioara, F.; Stoicanescu, D. Correlations between the Quality of Life Domains and Clinical Variables in Sarcopenic Osteoporotic Postmenopausal Women. J. Clin. Med. 2020, 9, 441.

12. Shieh, A.; Bastrom, T.; Roocroft, J.; Edmonds, E.W.; Pennock, A.T. Meniscus tear patterns in relation to skeletal immaturity: children versus adolescents. Am. J. Sports Med. 2013, 41, 2779 2783.

13. Andrish, J.T. Meniscal Injuries in Children and Adolescents: Diagnosis and Management. JAAOS - J. Am. Acad. Orthop. Surg. 1996, 4, 231-237.

14. Wessel, L.M.; Scholz, S.; Rüsch, M. Characteristic Pattern and Management of Intraarticular Knee Lesions in Different Pediatric Age Groups. J. Pediatr. Orthop. 2001, 21.

15. Kay, J.; Memon, M.; Marx, R.G.; Peterson, D.; Simunovic, N.; Ayeni, O.R. Over $90 \%$ of children and adolescents return to sport after anterior cruciate ligament reconstruction: a systematic review and meta-analysis. Knee Surgery, Sport. Traumatol. Arthrosc. 2018, 26, 1019-1036.

16. Sepúlveda, F.; Sánchez, L.; Amy, E.; Micheo, W. Anterior Cruciate Ligament Injury: Return to Play, Function and Long-Term Considerations. Curr. Sports Med. Rep. 2017, 16, 172-178.

17. Bauer, M.; Feeley, B.T.; Gallo, R.A. Effect of Academic Grade Level on Return to Athletic
Competition After Anterior Cruciate Ligament Reconstruction. J. Pediatr. Orthop. 2019, 39, 198-201.

18. Sousa, P.L.; Krych, A.J.; Cates, R.A.; Levy, B.A.; Stuart, M.J.; Dahm, D.L. Return to sport: Does excellent 6-month strength and function following ACL reconstruction predict midterm outcomes? Knee Surgery, Sport. Traumatol. Arthrosc. 2017, 25, 1356-1363.

19. Bellisari, G.; Samora, W.; Klingele, K. Meniscus Tears in Children. Sports Med. Arthrosc. 2011, 19, 50-55.

20. Ardern, C.L.; Ekås, G.; Grindem, H.; Moksnes, H.; Anderson, A.; Chotel, F.; Cohen, M.; Forssblad, M.; Ganley, T.J.; Feller, J.A.; et al. 2018 International Olympic Committee consensus statement on prevention, diagnosis and management of paediatric anterior cruciate ligament (ACL) injuries. Knee Surg. Sports Traumatol. Arthrosc. 2018, 26, 989-1010.

21. Onofrei, R.R.; Amaricai, E.; Petroman, R.; Surducan, D.; Suciu, O. Preseason Dynamic Balance Performance in Healthy Elite Male Soccer Players. Am. J. Mens. Health 2019, 13, 1557988319831920.

22. Mușat, A.; Popa, Z.; Craina, M.-L.; Onofrei, R.R.; Luca, C.T.; Bonte, D.C.; Pantea, C.; Stelea, L.; Petre, I. Identification Of Postural Changes During Pregnancy By Using Baropodometry - Case Presentation. In Proceedings of the The XV Conference of the Romanian-German Society of Obstetrics and Gynecology, Timisoara, 6-8 June 2019; Anastasiu, D., Craina, M., Hudita, D., Russu, M., Eds.; Filodiritto Publisher - International Proceedings: Timisoara, 2019; pp. 329-332. ISBN 978-88-85813-76-2.

23. Roman, N.; Tirziman, E.; Sorea, D.; Miclaus, R.; Repanovici, A.; Amaricai, E.; Rogozea, L. Ethical dilemmas in the interdisciplinary approach to informed consent to patients in physiotherapy services in Romania. Rev. Cercet. si Interv. Soc. 2018, 63, 290-303.

24. Beck, N.A.; Patel, N.M.; Ganley, T.J. The pediatric knee: current concepts in sports medicine. J. Pediatr. Orthop. B 2014, 23, 5966.

25. Nicodin, A.; Boia, E.S.; Popoiu, M.C.; Cozma, G.; Nicodin, G.; Badeti, R.; Trailescu, M.; Adam, O.; David, V.L. Preliminary results after Nuss procedure. Chir. 2010, 105, 203-210. 